\title{
Black fungi and ants: a genomic comparison of species inhabiting carton nests versus domatia
}

\author{
Yu Quan 1,2,3 (10, Nickolas Menezes da Silva ${ }^{6}$, Bruna Jacomel Favoreto de Souza Lima ${ }^{5,7}$, Sybren de Hoog 1,3,5, \\ Vania Aparecida Vicente ${ }^{5,7}$, Veronika Mayer ${ }^{6}$, Yingqian Kang ${ }^{3,4^{*}}$ and Dongmei Shi ${ }^{2^{*}}$
}

\begin{abstract}
Some members of Chaetothyriales, an order containing potential agents of opportunistic infections in humans, have a natural habitat in nests of tropical arboreal ants. In these black fungi, two types of ant symbiosis are known, i.e. occurrence in domatia inside living plants, or as components of carton constructions made of ant-chewed plant tissue. In order to explain differences between strains from these types of association, we sequenced and annotated genomes of two newly described carton species, Incumbomyces lentus and Incumbomyces delicatus, and compared these with genomes of four domatia species and related Chaetothyriales. General genomic characteristics, CYP genes, carbohydrate-active enzymes (CAZymes), secondary metabolism, and sex-related genes were included in the study.
\end{abstract}

Keywords: Black fungi, Carton fungi, Chaetothyriales, Comparative genomics

\section{Introduction}

Ants (Arthropoda: Formicidae) are ubiquitous in nearly all climate zones worldwide and play important roles in many ecosystems. The sum of ant bodies has been estimated to account for $15-20 \%$ of terrestrial animal biomass (Schultz 2000). Interactions between ants and fungi were already recorded more than 100 years ago (Bailey 1920; Huxley 1978; Miehe 1911). These not only concern the Attine-fungi mutualistic symbioses in general in fungus gardens (Mueller et al. 2018), but a wide diversity of less pronounced interactions occur (Biedermann and Vega 2020; Moreau 2020). Among the black fungi, Cladosporium myrmecophilum is a classical colonizer

\footnotetext{
*Correspondence: 449164105@qq.com; shidongmei28@163.com 2 Department of Dermatology and Laboratory of Medical Mycology, Jining No. 1 People's Hospital, Shandong, China

${ }^{3}$ Key Laboratory of Environmental Pollution Monitoring and Disease Control, Ministry of Education of Guizhou and Guizhou Talent Base for Microbiology and Human Health, School of Basic Medical Sciences, Guizhou Medical University, Guiyang, China

Full list of author information is available at the end of the article
}

of debris in carton nests of Lasius fuliginosus (SchlickSteiner et al. 2008). Fungi identified with sequence data as belonging to the order Chaetothyriales were found a decade ago, when phialophora-like species were recurrently isolated from ants and their constructions (Little and Currie 2007; Defossez et al. 2009; Mayer et al. 2018). Many of these fungi seem to have ant-association as their main habitat choice, and many are new to science. Given the wide distribution, biodiversity and nesting activities of ant species, the fungi associated with these arthropods might also be quite diverse. The discovery and full description of these new species will have a profound impact on the current classification of Chaetothyriales.

The order Chaetothyriales (Ascomycota) is particularly known through the black yeasts and filamentous relatives that cause opportunistic infections in humans. The species in this order tend to be abundant in extreme or tannin-rich natural habitats. The best-known species, however, are the ones that are found in domesticated environments that are rich in creosote or toxic hydrocarbons (Döğen et al. 2013) or in habitats with high 
temperature and/or poor in nutrients (Gostinčar et al. 2012). This extremotolerance has been hypothesized to contribute to invasive abilities of sterile sites of the vertebrate body (Quan et al. 2020a, b). As ants produce and communicate with ketones and low-molecular hydrocarbons (Di Mauro et al. 2015) which also function as antimicrobial compounds in ant nests and constructions, the ants might have played a role in early evolution of extremophily observed in Chaetothyriales. While nine clades of the order have been redefined to family level (Quan et al. 2020a, b), the majority of species with close vicinity to ants, i.e. those residing in their nesting space provided by their host-plant (=domatia), clustered in a single, as yet poorly defined clade, which might deserve family status. Some additional domatia-associated species are found in the Trichomeriaceae. Species associated with carton exposed to the environment seem less specialized and are scattered in three families, i.e. Cyphellophoracere, Herpotrichiellaceae, and Trichomeriaceae (Voglmayr et al. 2011; Vasse et al. 2017). Morphologically, Incumbomyces species, as other carton strains, lack conidiation in culture, while domatia-fungi show a consistent type of sympodial propagation with mucous conidia (Voglmayr et al. 2011; Quan et al. 2020a, b). The morphological differences might be related to vectors of dispersal e.g. with ant bodies.

The deviating morphology and phylogenies of carton-versus domatia-associated black fungi suggests that Chaetothyriales have gone through different types of evolution with the ant as driver. Domatia are modified leaves, stems or roots that provide cavities occupied by ants, offered by about 680 species of tropical vascular plants. Once inhabited by ants, the domatia contain dark patches from which black fungi can be isolated (Nepel et al. 2016). Recent data show that colony-founding queens start growing chaetothyrialean fungi in the domatia already before they lay their eggs, and that the queens do not feed on fungal material themselves but feed it to the larvae (Mayer et al. 2018). The second type of association of ants and Chaetothyriales is referred to as carton nesting. Nests consist of chewed plant material and have a cardboard-like appearance. Fungal hyphae are abundantly found in the walls of nests and galleries and strengthen the constructions. The main function of the carton structure is to increase the space of the nest and to enhance defense strategies (Vasse et al. 2017). The fungi in these structures do not serve as food, but increase stability of the nests (Hölldobler and Wilson 1990).

Genome analysis and comparison is a widely used biotechnology and may provide clues towards understanding of microbial ecology. At present, 45 genomes of Chaetothyriales have been published. Teixeira et al. (2017) analyzed 23 genomes of Chaetothyriales and provided a detailed comparative analysis, revealing genes related to protein degradation, carbohydrate-active enzymes (CAZymes), melanin synthesis and secondary metabolism. Moreno et al. (2019) was the first to analyze genomes of Chaetothyriales from ant domatia. The domatia-associated species were found to have remarkably small genomes, low amounts of protein-coding genes, and a high degree of repetitive elements. In addition, the proportion of biosynthetic clusters involved in the production of secondary metabolites and potential antibacterial activities were overrepresented. Attili-Angelis et al. (2014) described some species from ant bodies rather than from nesting material; these genomes represent members of Cyphellophoraceae.

Two novel genomes in the present study were derived from CBS 128958 and CBS 129047, recently described as types of Incumbomyces lentus and I. delicatus, respectively, in the family Trichomeriaceae. Both originated from ant carton structures of ant species in tropical Southeast Asia structures (Voglmayr et al. 2011). Although carton fungi and domatia fungi both belong to Chaetothyriales, their positions within the order are markedly different. Habitat conditions within domatia are balanced, whereas carton structures are subjected to fluctuating environmental conditions. The difference in habitat choices of the black fungi may to have had profound evolutionary consequences. The aim of the present paper is to compare some parameters which may have played a role in these differential phylogenies.

\section{Materials and methods}

\section{Strains and sequencing}

Genomic DNA of Incumbomyces lentus CBS 128958, isolated from carton of a Monomorium sp. ant nest in Malaysia and I. delicatus CBS 129047, isolated from carton of a Crematogaster sp. ant nest in Thailand (Quan et al. 2020a, b) was extracted from cell pellets harvested from cultures incubated for 14 days at $28{ }^{\circ} \mathrm{C}$ with Fungi DNA Kit (Omega Bio-Tek, Norcross, GA, U.S.A.) according to the manufacturer's instructions. DNA concentration was quantified using a TBS-380 fluorometer (Turner BioSystems, Sunnyvale, CA, U.S.A.). High qualified DNA samples $\left(\mathrm{OD}_{260 / 280}=1.8-2.0,>6 \mu \mathrm{g}\right)$ were utilized to construct a fragment library with $400 \mathrm{bp}$ insert size. Sequencing was performed at Biozeron Biotechnology Company (Shanghai, China) on Illumina Hiseq and Pacific Bioscience platforms. Information of species included in the study is provided in Additional file 1: Table S1.

\section{Alignment and phylogenetic analysis}

The combined sequences of ITS and LSU of Chaetothyriales species in this study were obtained from NCBI 
and edited using BioEdit v7.2 (Hall 1999). Alignments were made by MAFFT v7 (http://mafft.cbrc.jp/) and optimized manually using Mega v7.2 (Kumar et al. 2012) and BioEDit v7.2. Missing data for partial or complete sequences in some taxa were coded as 'missing' (Wiens 2006). To address the phylogenetic relationships among taxa, Maximum Likelihood (ML) was used. Species of Melanina were taken as outgroups. The ML tree was obtained using RAxML-VI-HPC as implemented on the Cipres portal web server (http://www.phylo.org/). The tree was edited using Treeview v1.6.6 and completed with Adobe IlLuStrator CS v5.

\section{Genome assembly, repeat identification}

Raw sequencing data was generated by Illumina base calling software CASAVA v1.8.2 (http://support.illumina. com) with default settings. Contaminations of adaptors and primers were identified by TRImMOMATIC (http:// www.usadellab.org) with default parameters. Completeness of genomes was verified using ABYSS (http://www. bcgsc.ca) with multiple-Kmer parameters. GAPCLOSER software (https://sourceforge.net) was subsequently applied to fill remaining local gaps and correct SNPs for the final assembly. RePEATMASKer (http://www. repeatmasker.org/) with default parameters was used to identify genome repeat information (Stanke and Waack 2003). The genome sequences were submitted to NCBI with the accession numbers JACJVS000000000 (I. delicatus) and JACJVT000000000 (I. lentus).

\section{Gene prediction and functional annotation}

Genes of the studied isolates were predicted by ab initio prediction methods to obtain gene models for the organisms. Gene models were identified using Augustus (Stanke and Waack 2003). Cytochrome P450 monooxygenases (CYPs) were identified and annotated though CYPMiner, which is an automated computational pipeline for identification, classification, and downstream analyses of CYPs at the genome level (Kweon et al. 2020). According to the International P450 Nomenclatural Committee, a sequence identity of $>40 \%$ is regarded as the same family, and $>50 \%$ is regarded as the same subfamily. Carbohydrate-Active Enzymes (CAZymes) were identified using the DBCAN2 web server (Zhang et al. 2018). To identify and classify clusters of genes involved in the production of secondary metabolites, the genomes of the carton-associated species were mined by the ANTISMASH web server, fungal version 5.0 (https://fungi smash.secondarymetabolites.org; Blin et al. 2019). The mating type loci were characterized by homology to the MAT1-1 and MAT1-2 reference sequences previously described in Chaetothyriales.

\section{Results}

Phylogeny

The phylogenetic tree contains a total of 255 sequences including four of Melanina as outgroup (Additional file 2: Table S2). Two carton species, four domatia strains and 249 remaining Chaetothyriales species were analyzed. Throughout the tree, eight clades described at family level were recognized. Bootstrap values of each family are showed in Fig. 1. Carton strains are scattered throughout the tree, clustering in three families: Herpotrichiellaceae, Cyphellophoraceae and Trichomeriaceae. Most domatia strains clustered in a single clade together with two Cladophialophora species. A few domatia strains clustered in the family Trichomeriaceae, close to carton strains which are rather commonly found in the same family.

\section{Genome assembly and gene prediction}

Genome sequences of two Incumbomyces species originating from carton of ant nests were determined by Illumina and Pacific Bioscience and de novo assembled. After cleaning, a total of $27.1 \mathrm{Mb}$ and $31.5 \mathrm{Mb}$ high quality reads were generated for the strains CBS 128958 and CBS 129047, I. lentus and I. delicatus, respectively. GC contents were $50.78 \%$ (I. lentus) and $49.37 \%$ (I. delicatus), which is similar to most other black yeast species (Teixeira et al. 2017). Protein-coding gene compositions were determined by ab initio gene prediction methods. The highest gene count of 9530 genes was found in $I$. delicatus, which also had the largest genome of all antassociated species investigated $(31.5 \mathrm{Mb})$, whereas the domatia-associated strain CBS 134916 comprised only 6719 genes (Moreno et al. 2019). I. lentus was intermediate in having 8868 genes, similar to the species Arthrocladium fulminans (8534 genes), which belongs to Trichomeriaceae, i.e., the same family as carton fungi in Incumbomyces. Both average gene lengths of carton fungi (in bp) were similar, i.e., 1645 and 1637 bp. The number of tRNAs were different between the two studied strains. Numbers of tRNAs of carton strains (143-208) were much higher than those in domatia-associated strains (37-76). The contents of repetitive elements in I. lentus (CBS 128958) and I. delicatus (CBS 129047) were 1.75\% and $3.41 \%$, respectively, which was on average significantly higher than in other thus far sequenced species of Chaetothytiales without ant-related ecology (ranging from 0.03 to 5.2\%; Teixeira et al. 2017). In Arthrocladium fulminans, the repetitive elements comprised 1.75\%, while in domatia fungi percentages were very high, ranging from 4.09 to $16.32 \%$. All basic information of carton species, domatia species and Arthrocladium fulminans is listed in Table 1. Using ORTHOVENN2, we determined the core gene clusters that were conserved in both carton and 


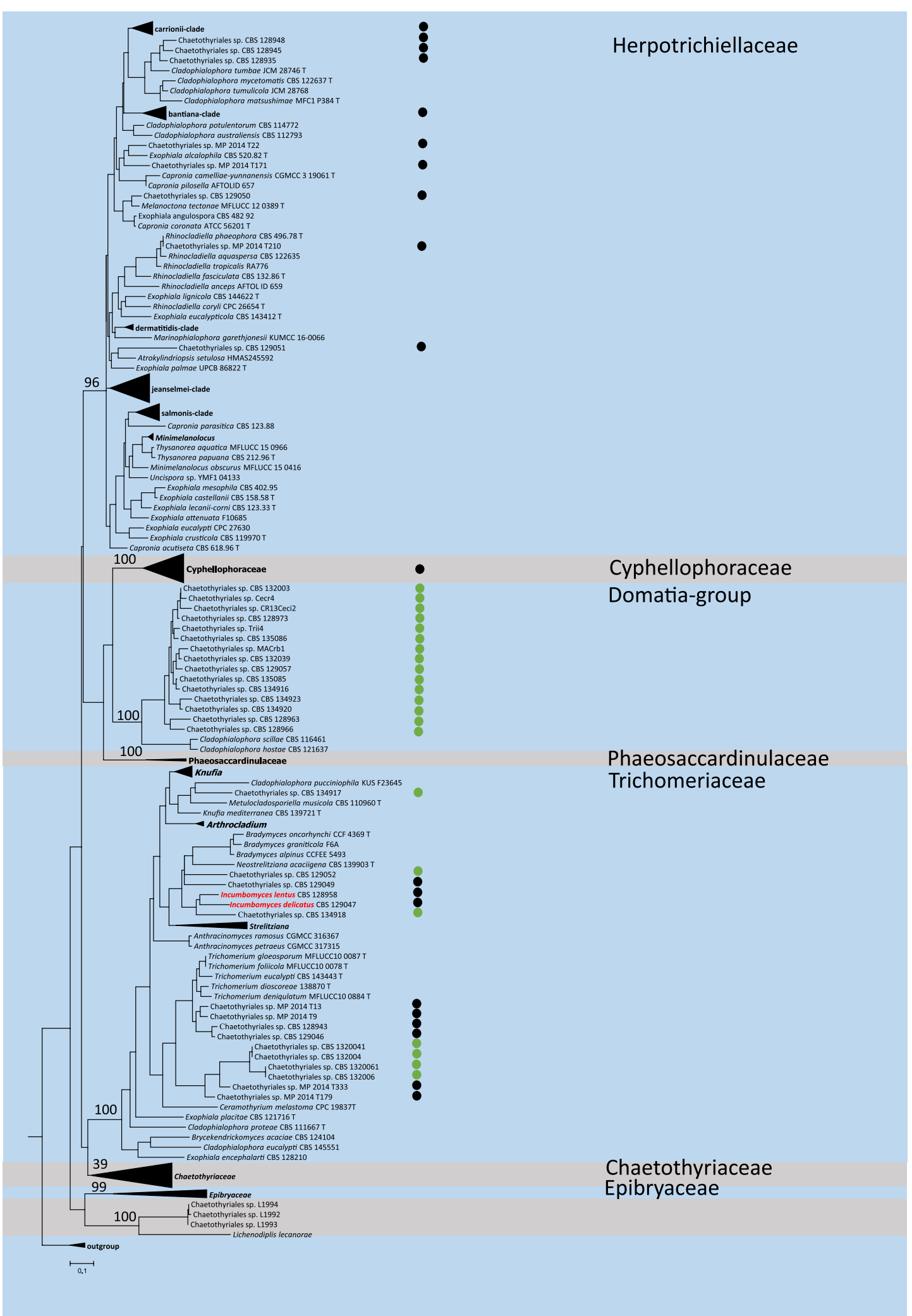

Fig. 1 Phylogenetic tree of Chaetothyriales based on ITS and LSU sequences, obtained by maximum likelihood. Four Melanina strains were used as outgroup. Green dots represent domatia fungi and black dots represent carton fungi 
Table 1 Statistics of compared genomes of ant-associated species and Arthrocladium sequenced in this study and by Moreno et al. (2019)

\begin{tabular}{|c|c|c|c|c|c|c|c|}
\hline Strain number & CBS 129047 & CBS 128958 & CBS 136243 & CBS 134916 & CBS 132003 & CBS 134920 & CBS 135597 \\
\hline Species & 1. delicatus & I. lentus & A. fulminans & $\begin{array}{l}\text { Chaetothyriales } \\
\mathrm{sp}\end{array}$ & $\begin{array}{l}\text { Chaetothyri- } \\
\text { ales sp }\end{array}$ & $\begin{array}{l}\text { Chaetothyriales } \\
\text { sp }\end{array}$ & $\begin{array}{l}\text { Chaetothyriales } \\
\text { sp }\end{array}$ \\
\hline Isolation source & Ant-carton & Ant-carton & Human patient & Domatium & Domatium & Domatium & Domatium \\
\hline $\begin{array}{l}\text { Gemone size } \\
\text { (Mbp) }\end{array}$ & 31.5 & 27.1 & 27.22 & 26.3 & 22.8 & 20.6 & 20.6 \\
\hline $\begin{array}{l}\% G+C \\
\text { content }\end{array}$ & $49.38 \%$ & $50 \%$ & $51.82 \%$ & 50.55 & 54.00 & 53.82 & 52.73 \\
\hline $\begin{array}{l}\text { N50 length } \\
\text { (bp) }\end{array}$ & $4,869,129$ & $3,707,458$ & $1,671,613$ & 60,287 & 312,613 & 164,768 & 570,188 \\
\hline Gene number & 9530 & 8868 & 8534 & 6719 & 5812 & 5988 & 5689 \\
\hline $\begin{array}{l}\text { Repetitive ele- } \\
\text { ments }\end{array}$ & $3.41 \%$ & $1.75 \%$ & $1.57 \%$ & $16.32 \%$ & $4.09 \%$ & $8.67 \%$ & $8.43 \%$ \\
\hline tRNAs & 143 & 208 & unknown & 37 & 43 & 76 & 60 \\
\hline NCBI number & JACJVS000000000 & JACJVT000000000 & GCA_003614865.1 & QQXO00000000 & QRBJ00000000 & QQSL00000000 & QQXN00000000 \\
\hline
\end{tabular}

domatia fungi, and in other species of Chaetothyriales. A range from 5586 to 13,269 orthologous clusters was detected among the 26 studied isolates, including carton fungi and domatia fungi (Fig. 2, Table 2). This resulted in 3096 clusters per genome in the core set conserved in all isolates. Among these, the average number of unique

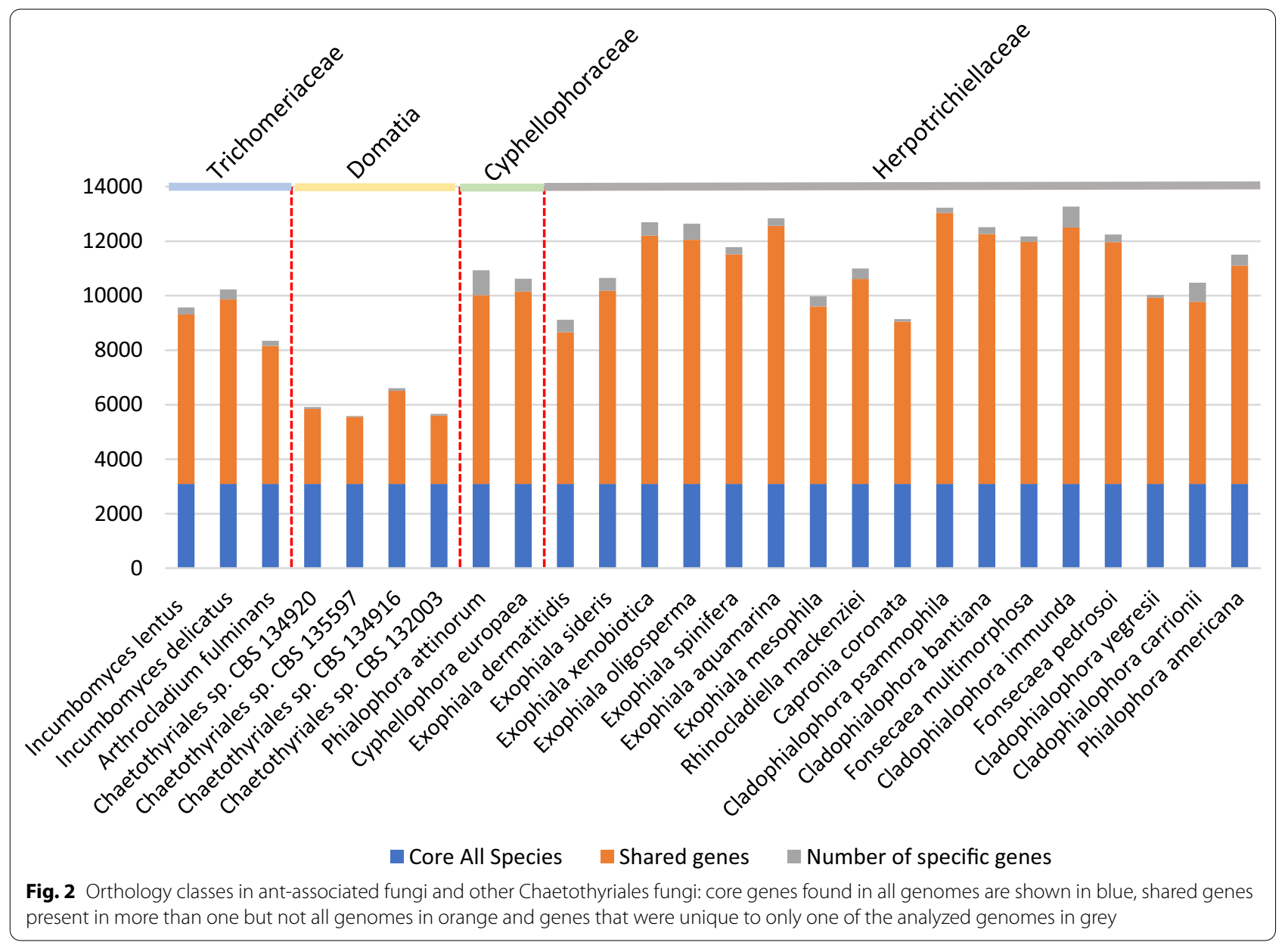


Table 2 The number of orthology classes in ant-associated fungi and other Chaetothyriales fungi, including core genes, shared genes, unique gene

\begin{tabular}{|c|c|c|c|c|}
\hline Species & $\begin{array}{l}\text { Number of genes in } \\
\text { orthogroups }\end{array}$ & Core all species & Shared genes & $\begin{array}{l}\text { Number } \\
\text { of specific } \\
\text { genes }\end{array}$ \\
\hline Incumbomyces lentus & 9570 & 3096 & 6214 & 260 \\
\hline Incumbomyces delicatus & 10,228 & 3096 & 6765 & 367 \\
\hline Arthrocladium fulminans & 8346 & 3096 & 5062 & 188 \\
\hline Chaetothyriales sp. CBS 134,920 & 5916 & 3096 & 2752 & 68 \\
\hline Chaetothyriales sp. CBS 135,597 & 5586 & 3096 & 2454 & 36 \\
\hline Chaetothyriales sp. CBS 134,916 & 6605 & 3096 & 3411 & 98 \\
\hline Chaetothyriales sp. CBS 132,003 & 5662 & 3096 & 2501 & 65 \\
\hline Phialophora attinorum & 10,935 & 3096 & 6926 & 913 \\
\hline Cyphellophora europaea & 10,622 & 3096 & 7054 & 472 \\
\hline Exophiala dermatitidis & 9117 & 3096 & 5560 & 461 \\
\hline Exophiala sideris & 10,650 & 3096 & 7084 & 470 \\
\hline Exophiala xenobiotica & 12,696 & 3096 & 9109 & 491 \\
\hline Exophiala oligosperma & 12,642 & 3096 & 8954 & 592 \\
\hline Exophiala spinifera & 11,783 & 3096 & 8421 & 266 \\
\hline Exophiala aquamarina & 12,839 & 3096 & 9464 & 279 \\
\hline Exophiala mesophila & 9977 & 3096 & 6511 & 370 \\
\hline Rhinocladiella mackenziei & 10,997 & 3096 & 7516 & 385 \\
\hline Capronia coronata & 9140 & 3096 & 5953 & 91 \\
\hline Cladophialophora psammophila & 13,227 & 3096 & 9937 & 194 \\
\hline Cladophialophora bantiana & 12,512 & 3096 & 9166 & 250 \\
\hline Fonsecaea multimorphosa & 12,173 & 3096 & 8881 & 196 \\
\hline Cladophialophora immunda & 13,269 & 3096 & 9409 & 764 \\
\hline Fonsecaea pedrosoi & 12,245 & 3096 & 8867 & 282 \\
\hline Cladophialophora yegresii & 10,023 & 3096 & 6832 & 95 \\
\hline Cladophialophora carrionii & 10,478 & 3096 & 6679 & 703 \\
\hline Phialophora americana & 11,507 & 3096 & 8009 & 402 \\
\hline
\end{tabular}

genes was 314 existing in the two carton fungi, while the average unique genes in domatia species only was 67 , and 188 clusters were represented in A. fulminans.

\section{Carbohydrate-active enzymes (CAZymes)}

CAZymes are responsible for the degradation, modification, and biosynthesis of carbohydrates and glycoconjugates (Cantarel et al. 2009). Based on amino-acid sequence and structure similarity, the CAZymes can be classified into five classes of enzyme activities and one associated module: glycoside hydrolases (GHs), glycosyl transferases (GTs), polysaccharide lyases (PLs), carbohydrate esterases (CEs), auxiliary activities (AAs), and the associated module carbohydrate-binding modules (CBMs) (Cantarel et al. 2009). The total numbers of genes in CAZymes families of I. lentus and I. delicatus are 288 and 293, respectively. This is higher than found in domatia fungi (ranging from 208 to 233), but comparable to members of Herpotrichiellaceae (ranging from
285 to 434) and A. fulminans in Trichomeriaceae (269) (Table 3).

Polysaccharide lyases (PLs) are a group of enzymes that cleave uronic acid-containing polysaccharide chains via a $\beta$-elimination mechanism to generate an unsaturated hexenuronic acid residue and a new reducing end. Both Incumbomyces carton strains possess the polysaccharide lyase subfamily 3 (PL3); the two domatia strains (CBS 135957 and CBS 134920) possess subfamily 4 (PL1), while two domatia strains (CBS 134916 and CBS 132003) were similar to most other Chaetothyriales, lacking pectinases; PL3 was so far detected only in Capronia coronata (Herpotrichiellaceae), a species originating from decorticated wood, and in Cyphellophora attinorum (Cyphellophoraceae), which was isolated from the cuticle of tropical ant gynes (Additional file 3: Table S3).

Glycoside hydrolases (GHs) are a widespread group of enzymes which hydrolyze the glycosidic bond between two or more carbohydrates or between a carbohydrate and a non-carbohydrate moiety. The number of $\mathrm{GH}$ 
Table 3 Composition of CAZymes in ant-associated and related chaetothyrialean fungi

\begin{tabular}{|c|c|c|c|c|c|c|c|}
\hline Species & GH & GT & CE & AA & CBM & PL & Total \\
\hline \multicolumn{8}{|l|}{ Trichomeriaceae } \\
\hline Incumbomyces lentus & 128 & 81 & 37 & 40 & 1 & 1 & 288 \\
\hline Incumbomyces delicatus & 135 & 79 & 38 & 39 & 1 & 1 & 293 \\
\hline Arthrocladium fulminans & 135 & 62 & 39 & 31 & 1 & 1 & 269 \\
\hline \multicolumn{8}{|l|}{ Domatia } \\
\hline Chaetothyriales sp. CBS 134920 & 87 & 74 & 30 & 30 & 1 & 1 & 223 \\
\hline Chaetothyriales sp. CBS 135597 & 85 & 74 & 26 & 33 & 1 & 1 & 220 \\
\hline Chaetothyriales sp. CBS 134916 & 96 & 76 & 30 & 30 & 1 & 0 & 233 \\
\hline Chaetothyriales sp. CBS 132003 & 86 & 68 & 27 & 26 & 1 & 0 & 208 \\
\hline \multicolumn{8}{|l|}{ Cyphellophoraceae } \\
\hline Phialophora attinorum & 151 & 98 & 69 & 66 & 3 & 1 & 388 \\
\hline Cyphellophora europaea & 173 & 96 & 62 & 72 & 3 & 1 & 407 \\
\hline Exophiala dermatitidis & 118 & 87 & 39 & 37 & 2 & 2 & 285 \\
\hline \multicolumn{8}{|l|}{ Herpotrichiellaceae } \\
\hline Exophiala xenobiotica & 181 & 110 & 70 & 67 & 4 & 2 & 434 \\
\hline Exophiala oligosperma & 161 & 123 & 73 & 61 & 3 & 0 & 421 \\
\hline Exophiala spinifera & 146 & 106 & 71 & 50 & 2 & 1 & 376 \\
\hline Exophiala aquamarina & 162 & 96 & 84 & 63 & 4 & 0 & 409 \\
\hline Exophiala mesophila & 118 & 102 & 49 & 52 & 1 & 0 & 322 \\
\hline Rhinocladiella mackenziei & 119 & 76 & 53 & 58 & 4 & 1 & 311 \\
\hline Capronia coronata & 112 & 84 & 52 & 34 & 3 & 2 & 287 \\
\hline Capronia epimyces & 104 & 89 & 61 & 44 & 1 & 0 & 299 \\
\hline Cladophialophora psammophila & 141 & 91 & 78 & 77 & 3 & 0 & 390 \\
\hline Cladophialophorabantiana & 143 & 90 & 66 & 70 & 3 & 0 & 372 \\
\hline Fonsecaea multimorphosa & 140 & 90 & 68 & 77 & 2 & 0 & 377 \\
\hline Cladophialophora immunda & 148 & 101 & 64 & 71 & 2 & 0 & 386 \\
\hline Fonsecaea pedrosoi & 133 & 89 & 81 & 65 & 2 & 0 & 370 \\
\hline Cladophialophora yegresii & 129 & 82 & 46 & 48 & 2 & 0 & 307 \\
\hline Cladophialophora carrionii & 137 & 87 & 43 & 50 & 3 & 1 & 321 \\
\hline Capronia semiimmersa & 140 & 94 & 51 & 54 & 3 & 0 & 342 \\
\hline
\end{tabular}

GH: glycoside hydrolases, GT: glycosyl transferases, CE: carbohydrate esterases, AA: auxiliary activities, CBM: associated carbohydrate-binding modules, PL: polysaccharide lyases

families of the carton fungi are 128 and 135, more than that present in domatia fungi (85-96; Table 3). GH families that exist in carton fungi but are absent from domatia fungi are GH27, GH36, GH79, and GH92. GH 27 and GH 36 mainly associated with galactosidase-related enzymes. GH 79 associated with glucuronidase-related enzymes, and GH92 are mainly focused on mannosidase.

Glycosyltransferases (GTs) are enzymes that catalyze the transfer of sugar moieties from activated donor molecules to specific acceptor molecules, forming glycosidic bonds. On average, members of Herpotrichiellaceae contain somewhat larger numbers $(76-123$, av. 93.9) than remaining members of Chaetothyriales (62-98, av. 78.7). A similar difference was observed with carbohydrate esterases (CEs), members of Herpotrichiellaceae having 39-84 (av. 61.7), against 26-69 (av. 39.8) for remaining species. Exophiala dermatitidis was consistently exceptional in Herpotrichiellaceae, having genome size and gene numbers like Incumbomyces species (Table 3).

The AA class presently groups nine families of ligninolytic enzymes and 6 families of lytic polysaccharide mono-oxygenases. A notable difference was observed in the numbers of AA7 of carton fungi being 14, while only 3-7 AA7 were present in domatia fungi.

\section{Cytochrome p450 genes (CYPs)}

Cytochrome p450 genes exist widely in all kingdoms and play important roles in primary and secondary metabolism, and in drug and xenobiotic resistance. Our study used CYPMINER, an automatic tool that allows processing of large numbers of sequence data to identify and classify CYPs. The identification results of CYPMINER are more detailed and abundant than with use of the previous database, the PFAM protein family database. Analyzing 
the domatia strain, CBS 135597, 51 families were identified using the CYPMINER tool, while only 14 results were obtained using the PFAM database. In order to compare CYPs in the carton fungi under study, we analyzed two domatia strains and nine additional species of Chaetothyriales (Table 4). A total of 216 CYP genes clustering in 130 families and 118 subfamilies were identified in the two Incumbomyces carton species. The number of CYPs of two carton species is slightly lower than that of two domatia strains, namely 105 (CBS 128958) and 111 (CBS 128047) in Incumbomyces, vs. 139 (CBS 135597) and 128 (CBS 134916) in domatia strains. The number of CYPs genes in compared members of Trichomeriaceae and Herpotrichiellaceae ranged from 117 (Arthroderma fulminans) to 322 (Cladophialophora psammophila). This result indicates that the CYP genes have significantly expanded in members of Herpotrichiellaceae. Those CYPs could not be assigned to any of the already defined CYP (sub)families and were therefore treated as new (sub)families. A total of five new families were detected in both carton strains, while the number of subfamilies was 42 (in I. lentus) and 44 (in I. delicatus). These numbers remain lower than those observed in other Chaetothyriales, mainly Herpotrichiellaceae, where they range from 65 to 170 .

The CYPs families of carton and domatia species are very similar (Additional file 4: Table S4). One of the main differences concerns CYP 6001, which is present in carton fungi but absent from domatia fungi. The CYPs are also close to those of Arthrocladium fulminans, a member of the same family as Incumbomyces, Trichomeriaceae, and solely known from an infection in a human patient. A. fulminans has four more CYP families (CYP5199, CYP570, CYP619, CYP60) compared to domatia species; the remaining CYPs are shared. Seven CYPs (CYP5076, CYP5077, CYP5081, CYP5282, CYP5295, CYP5307, CYP631) were found only in domatia and were lacking in other members of Chaetothyriales. Most of these genes are related to xenobiotic or secondary metabolism (Chadha et al. 2018).

\section{Secondary metabolism}

Secondary metabolism refers to the metabolic pathways and small molecular products involved in ecological interaction, which are not essential for the survival of the organism but may be significant, e.g. for the colonization of a specific niche. Summarizing the wide diversity of secondary metabolites, the following broad types can be distinguished according to enzymes involved in synthetic pathways: polyketides (PKS), non-ribosomal peptides (NRPS), and terpenes and indole alkaloids (Keller et al. 2005). Several of the sequenced fungal genomes contained hybrid genes, such as PKS-NRPS. Incumbomyces delicatus and I. lentus possess 7 and 8 biosynthetic clusters, respectively (Fig. 3, Table 5). The NRPS type is prevalent in clusters of both carton species. The type III PKS cluster (t3 PKS), previously reported in Herpotrichiellaceae, Cyphellophoraceae, and Trichomeriaceae is absent from carton and domatia species. In addition, both species had only one or two I PKS, which is far less

Table 4 Distribution of CYP p450 genes in in ant-associated fungi and other Chaetothyriales fungi

\begin{tabular}{|c|c|c|c|c|c|c|c|}
\hline Species & Ecology & Genes of family & $\begin{array}{l}\text { Genes of } \\
\text { new family }\end{array}$ & $\begin{array}{l}\text { Genes of } \\
\text { total family }\end{array}$ & $\begin{array}{l}\text { Genes of } \\
\text { subfamily }\end{array}$ & $\begin{array}{l}\text { Genes of new } \\
\text { subfamily }\end{array}$ & Total genes \\
\hline \multicolumn{8}{|l|}{ Trichomeriaceae } \\
\hline Incumbomyces lentus & Carton & 58 & 5 & 63 & 15 & 42 & 105 \\
\hline Incumbomyces delicatus & Carton & 62 & 5 & 67 & 17 & 44 & 111 \\
\hline Arthrocladium fulminans & Patient & 66 & 6 & 72 & 20 & 45 & 117 \\
\hline \multicolumn{8}{|l|}{ Domatia } \\
\hline Chaetothyriales sp. CBS 135597 & Domatia & 74 & 9 & 83 & 27 & 56 & 139 \\
\hline Chaetothyriales sp. CBS 134916 & Domatia & 68 & 6 & 74 & 19 & 54 & 128 \\
\hline \multicolumn{8}{|l|}{ Cyphellophoraceae } \\
\hline Cyphellophora attinorum & Ant & 116 & 9 & 125 & 26 & 88 & 213 \\
\hline \multicolumn{8}{|l|}{ Herpotrichiellaceae } \\
\hline Exophiala xenobiotica & Oil sludge & 142 & 18 & 160 & 33 & 108 & 268 \\
\hline Exophiala oligosperma & Patient & 116 & 20 & 136 & 28 & 94 & 230 \\
\hline Rhinocladiella mackenziei & Patient & 135 & 25 & 160 & 35 & 109 & 269 \\
\hline Capronia coronata & Wood & 81 & 9 & 90 & 29 & 61 & 151 \\
\hline Cladophialophora psammophila & Polluted soil & 178 & 18 & 196 & 44 & 126 & 322 \\
\hline Cladophialophora bantiana & Patient & 139 & 16 & 155 & 35 & 99 & 254 \\
\hline Fonseceae pedrosoi & Patient & 142 & 11 & 153 & 49 & 44 & 197 \\
\hline
\end{tabular}




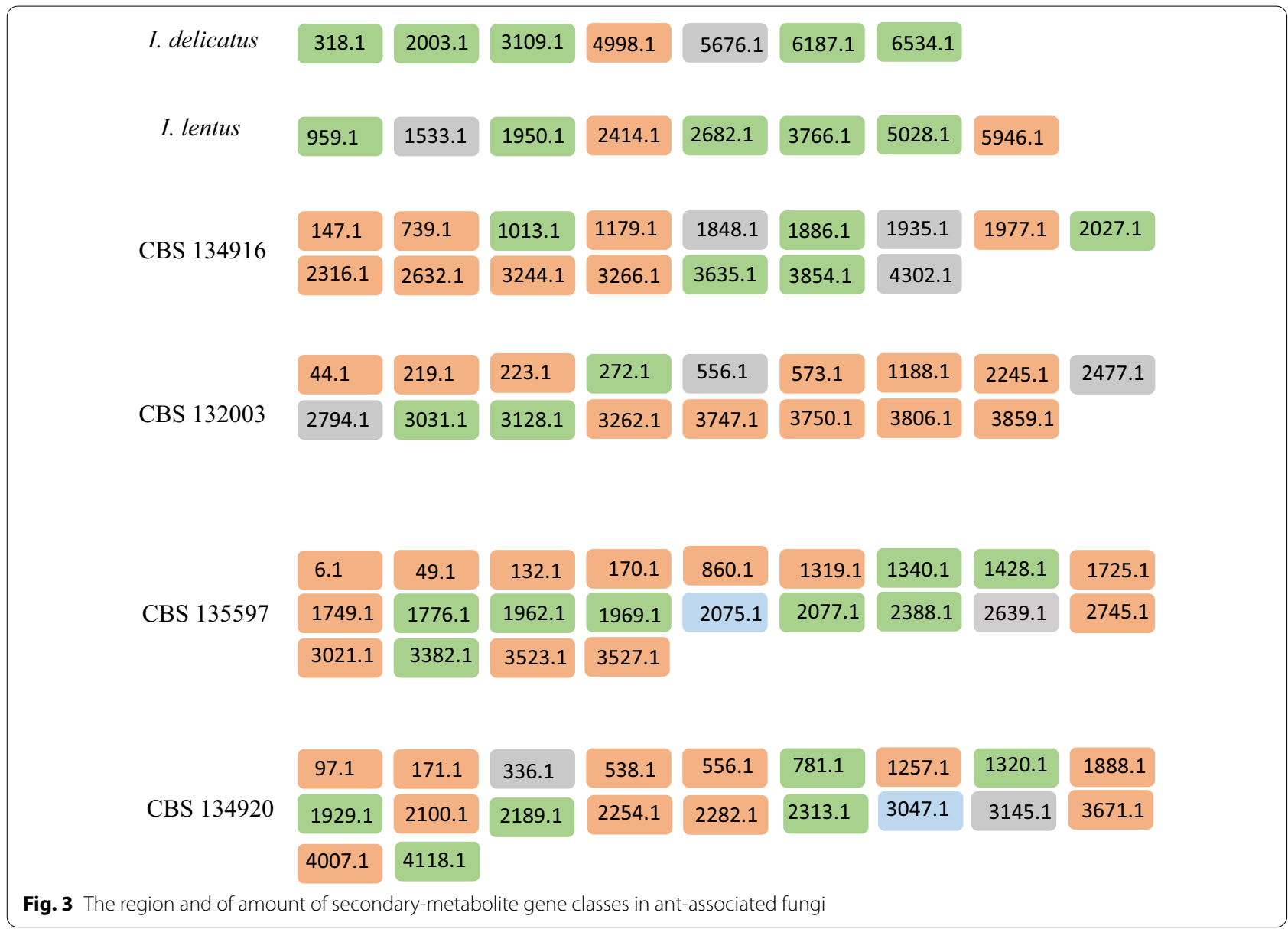

Table 5 Summary of secondary-metabolite gene classes in ant-associated fungi

\begin{tabular}{|c|c|c|c|c|c|c|}
\hline Species & Terpene & III PKS & IPKS & III PKS/I PKS & NRPS & I PKS/NRPS \\
\hline Incumbomyces lentus & 1 & 0 & 2 & 0 & 5 & 0 \\
\hline Incumbomyces delicatus & 1 & 0 & 1 & 0 & 5 & 0 \\
\hline Chaetothyriales sp CBS 134916 & 3 & 0 & 8 & 0 & 5 & 0 \\
\hline Chaetothyriales sp CBS 132003 & 3 & 0 & 11 & 0 & 3 & 0 \\
\hline Chaetothyriales sp CBS 134920 & 2 & 0 & 11 & 0 & 6 & 1 \\
\hline Chaetothyriales sp CBS 135597 & 1 & 0 & 12 & 0 & 8 & 1 \\
\hline
\end{tabular}

than observed in domatia strains (11 on average). The number of terpenes in Incumbomyces was also far less than in remaining Chaetothyriales (Teixeira et al. 2017).

\section{Asexual and sexual reproduction}

The mating type locus is a unique region in the fungal genome, playing a central role in the sexual cycle. We identified the mating type idiomorph, flanking genes and heterokaryon incompatibility protein (HET-PF06985) in the genomes of Incumbomyces carton fungi and compared these with four domatia species and other members of Chaetothyriales described previously. In none of the Incumbomyces species, sporulation has been observed, neither sexual nor clonal (Quan et al. 2020a, b). I. delicatus (CBS 129047) contained a single mating type (MAT1-2) and thus was found to be heterothallic. In contrast, I. lentus (CBS 128958) was confirmed to have both MAT1-1 and MAT1-2, which were closely clustered in a single assembled scaffold; hence Incumbomyces lentus was homothallic (Fig. 4). 


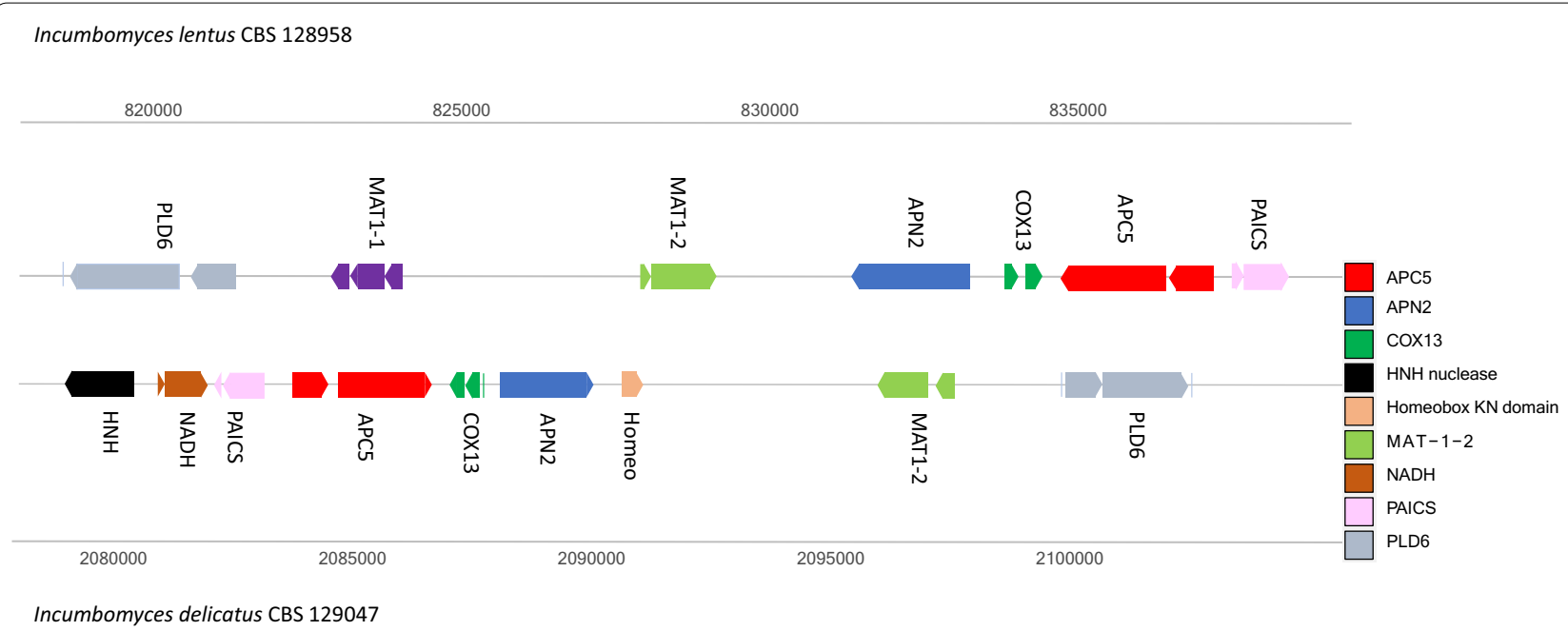

Fig. 4 Mating type locus structure and flanking regions of two carton species

We confirmed the MAT flanking genes APN2, APC5, $S L A 2$ and $C O X 13$, which are highly conserved and are distributed widely in members of Eurotiomycetes (Coppin et al. 1997; Fraser et al. 2007; Paoletti et al. 2007). Nevertheless, significant differences in the flanking structure were observed between the two Incumbomyces species. In I. lentus CBS 128958, the APN2, COX13, and APC5 genes were in synteny in the right flanking region, while in I. delicatus CBS 129047 they were in the left flanking region, in inversed order. The SLA2 genes of these two species were not close to other flanking genes. Concerning I. lentus, the MAT locus is localized in scaffold 5 (SLA2 in scaffold 2). In I. delicatus, the MAT locus is localized in scaffold 8 (SLA2 in scaffold 6). Both carton species have the COX13 genes, which are absent from most Chaetothyriales but present in domatia fungi and in members of Trichomeriaceae, i.e. in Incumbomyces and in A. fulminans. The heterokaryon incompatibility protein (HET) ranged from 73 in I. lentus to 105 in I. delicatus. In contrast, the number in domatia strains ranged from 10 in CBS 134920 to 31 in CBS 134916. In other species of Chaetothyriales, the number was extremely variable, ranging from 1 to 134 (Additional file 5: Table S5).

\section{Enzymes representing specific types of ecology}

To better understand the ecology of carton fungi and other Chaetothyriales, we selected five types of enzymes, representing specific types of ecology, and listed the number of genes in each category, such as cellulases and pectinases (plant-associated compounds), lipases (animal-associated compounds), chitinases (potentially involved in decomposition of chitinous ant bodies), and ligninolytic enzymes (involved in wood degradation). An observation which is difficult to explain is that A. fulminans, only known from human infection, is unique in Chaetothyriales by having 12 pectinase genes (Table 6).

\section{Discussion}

The genus Incumbomyces, containing two described species isolated from walls of ant-made carton nests (Quan et al. 2021), clusters phylogenetically among members of Trichomeriaceae, as a sister group of Bradymyces. It may be questioned whether the genus shows highest similarity with its family members due to shared phylogeny, or with ant-associated Chaetothyriales sharing a similar habitat. The only member of the Trichomeriaceae for which a genome has been sequenced is Arthrocladium fulminans (Moreno et al. 2020). This species is rather exceptional in Trichomeriaceae, being known from two isolates that caused severe infections in humans (Diallo et al. 2017; Egenlauf et al. 2019), while most members of the family comprise surface-colonizing 'sooty moulds' (Chomnunti et al. 2012). In addition to this life style, a significant number of ant-associated species-both carton- and domatia-associated-clustered in the family (Fig. 1). Another group combining oligotrophic surface colonization with pathogenicity is Bradymyces, where an infection in fish was described (Hubka et al. 2014). An interesting analogy of oligotrophy and infectious ability was published by Moreno et al. (2019), hypothesizing an environmental habitat of the neuroinvasive species Rhinocladiella mackenziei in the hydrocarbon-polluted desert. The expanded cytochromes may be instrumental in these seemingly very different life styles. In addition to cytochromes, the species also had choline permease 
Table 6 The number of five types of enzymes, representing specific types of ecology in each category

\begin{tabular}{|c|c|c|c|c|c|c|}
\hline Species & Strain number & Cellulases & Lipases & Chitinases & Ligininolytic & Pectinases \\
\hline Incumbomyces lentus & CBS 128958 & 7 & 22 & 3 & 8 & 0 \\
\hline Incumbomyces delicatus & CBS 129047 & 8 & 20 & 5 & 8 & 0 \\
\hline Arthrocladium fulminans & CBS 136243 & 11 & 44 & 28 & 33 & 12 \\
\hline Chaetothyriales sp. & CBS 135597 & 9 & 16 & 10 & 7 & 0 \\
\hline Chaetothyriales sp. & CBS 134916 & 11 & 15 & 5 & 9 & 0 \\
\hline Phialophora attinorum & CBS 131958 & 15 & 53 & 6 & 9 & 0 \\
\hline Phialophora europaea & CBS 101466 & 17 & 32 & 7 & 11 & 0 \\
\hline Exophiala dermatitidis & $\mathrm{NIH} 8656$ & 9 & 21 & 5 & 7 & 0 \\
\hline Exophiala sideris & CBS 121828 & 11 & 27 & 5 & 7 & 0 \\
\hline Exophiala xenobiotica & CBS 118157 & 13 & 34 & 7 & 10 & 0 \\
\hline Exophiala oligosperma & CBS 725.88 & 8 & 36 & 6 & 10 & 0 \\
\hline Exophiala spinifera & CBS 89968 & 8 & 43 & 5 & 9 & 0 \\
\hline Exophiala aquamarina & CBS 119918 & 13 & 50 & 6 & 7 & 0 \\
\hline Exophiala mesophila & CBS 402.95 & 11 & 16 & 4 & 9 & 0 \\
\hline Rhinocladiella mackenziei & CBS 650.93 & 11 & 27 & 2 & 6 & 0 \\
\hline Capronia coronata & CBS 617.96 & 11 & 21 & 5 & 8 & 0 \\
\hline Cladophialophora psammophila & CBS 110553 & 12 & 40 & 4 & 12 & 0 \\
\hline Cladophialophora bantiana & CBS 173.52 & 11 & 35 & 4 & 12 & 0 \\
\hline Fonsecaea multimorphosa & CBS 102226 & 12 & 31 & 3 & 10 & 0 \\
\hline Cladophialophora immunda & CBS 834.96 & 11 & 24 & 3 & 13 & 0 \\
\hline Fonsecaea pedrosoi & CBS 271.37 & 10 & 29 & 4 & 11 & 0 \\
\hline Cladophialophora yegresii & CBS 114405 & 14 & 28 & 3 & 9 & 0 \\
\hline Cladophialophora carrionii & CBS 160.54 & 13 & 30 & 3 & 8 & 0 \\
\hline Phialophora americana & CBS 27337 & 14 & 38 & 3 & 8 & 0 \\
\hline
\end{tabular}

Cellulases representing the ecology related to plant-associated compounds, lipases representing the ecology related to animal-associated compounds, chitinases potentially involved in decomposition of chitinous ant bodies, ligninolytic enzymes involved in wood degradation

which assists in conversion to the osmoprotectant glycine betaine, enhancing survival in the desert. Numerous members of Chaetothyriales, particularly those in Herpotrichiellaceae and scattered in other families, are environmental but predisposed for infection by their melanin, extremotolerance and hydrocarbon assimilation, being pronounced opportunists. The evolution of genes involved in colonization of these habitats deserves attention. Ant domatia are rich in low-molecular volatiles with low toxicity (Prenafeta et al. 2021), which may have been an evolutionary starting point, but more data are needed from comparable species in Trichomeriaceae.

For some general genomic characters, such as genome size, GC content, and gene number, the carton fungi in Incumbomyces proved to be similar to A. fulminans. The domatia fungi ("domata-group" in Fig. 1) differ significantly from all remaining Chaetothyriales known thus far by having small genomes containing a limited number of genes (Moreno et al. 2019; Table 1). The GH families i.e. GH27, GH36, GH79, and GH92 are mostly linked to decomposition of polysaccharides in plant cell walls. Ant nests and tunnels inhabited by Incumbomyces species consist of wood pulp that has been chewed by the ants, whereby the fungal hyphae enhance constructive strength. A CAZy difference between carton and domatia concerns AA7 enzymes in AA class. The amount of these enzymes in carton is much more than that in domatia. Known AA7 enzymes are potentially involved in the biotransformation or detoxification of lignocellulosic compounds (Levasseur et al. 2013). Carton also consists of ant-chewed wood and other plant material, while this material is absent from domatia. Indeed, the total number of CAZymes in carton fungi is higher than that in domatia fungi, indicating that carton fungi have more enzymes to decompose plant material and to synthesize fungal cell components. The habitat of ant debris inside domatia apparently does not require these enzymes.

Ants secrete pheromones such as low-molecular hydrocarbons and ketones (David Morgan 2009) to protect the brood against fungal and bacterial pathogens. Many fungi can be isolated from the nests as their propagules are easily trapped in the complex networks, but few are able to grow in this environment. However, members of Chaetothyriales seem relatively resistant 
to these compounds, allowing them to colonize the somewhat toxic ant constructions (Mayer et al. 2018). Teixeira et al. (2017) observed cytochrome (CYP) family expansion in Chaetothyriales. The authors actually only analyzed members of Herpotrichiellaceae, a family with a strong association with domestic environments polluted with aromatic hydrocarbons (Isola et al. 2013). CYP expansion is consistent with this habitat. For example, CYP 530 is thought to participate in the degradation of several fatty acids and hydrocarbons. It was found with 12 copies in Cladophialophora psammophila, a species known from a single isolate from hydrocarbon-polluted soil. This CYP was not found in any of the carton or domatia strains, suggesting that the fungi, reside in a lower-toxic habitat. This absence may be evolutionarily ancestral, as chaetothyrialean members in the derived family Herpotrichiellaceae that survive in hydrocarbon-polluted domesticated environments have shown significant expansion of CYP genes (Teixeira et al. 2017).

Very large differences related to secondary metabolism were noted between species, even among species sharing a similar ecology. Carton and domatia fungi are associated to ants, the enzymes related to the secondary metabolism of both fungi are very different. Particularly the differences in I PKS and NRPS are significant (Fig. 3). The exact ecological meaning of these differences is as yet unclear and needs comparison with additional members of Trichomeriaceae from other habitats.

Similar to most species of Trichomeriaceae, sporulation in vitro is nearly absent from cultured Incumbomyces species. Only a few species are known by their Trichomerium sexual states in the natural habitat (Chomnunti et al. 2012). Incumbomyces lentus has both MAT1-1 and MAT1-2, a condition thus far only proven in sexual Capronia species (Teixeira et al. 2017). The species may thus have a homothallic sexual cycle in nature. The other carton species, I. delicatus only has a single $M A T$ gene, with a structure similar with domatia species and $A$. fulminans. Among the known species of Chaetothyriales, only those isolated via their sexual state in nature (Capronia semimmersa, $C$. epimyces and $C$. coronata) have been proven to harbor two mating type genes, while all asexual species described to date have only a single mating type gene (Teixeira et al. 2017). Also the four domatia strains and Arthrocladium fulminans in Trichomeriaceae harbored only a single MAT gene (Moreno et al. 2019). The MAT locus of the two species of Incumbomyces is remarkably different, with a large translocation in $I$. lentus where APN2, COX13 and APC5 are in the right flanking region. In I delicatus they are in the left flanking region as in Arthrocladium and domatia fungi, but in different order. In general, the MAT location is extremely variable in Chaetothyriales (Teixeira et al. 2017) for reasons which have not been clarified.

\section{Supplementary Information}

The online version contains supplementary material available at https://doi. org/10.1186/s43008-022-00091-5.

Additional file 1: Table S1. Basic information of Chaetothyriales species included in the study.

Additional file 2: Table S2. The GenBank data of strains in this study.

Additional file 3: Table S3. Specific genes of CAZymes in ant-associated fungi and other Chaetothyriales fungi.

Additional file 4: Table S4. Specific genes of Cytochrome P450 in antassociated fungi and other Chaetothyriales fungi.

Additional file 5: Table S5. The numbers of Heterokaryon incompatibility protein (HET-PF06985) in Chaetothyriales.

\section{Acknowledgements}

Not applicable.

\section{Authors' contributions}

YQ and SH were major contributors in writing the manuscript. YQ NS and BJF analyzed the data. W, VM, YQK, and DMS modified and improved the manuscript. All authors read and approved the final manuscript.

\section{Funding}

This work was supported by the 111 Project (D20009); National Natural Science Foundation of China (NSFC; no. 32060034); International Science and Technology Cooperation Base of Guizhou Province ([2020]4101); Guizhou Scientific Plan Project ([2020]4Y220); Guizhou Scientific Plan Project [(2019) 2873]; Talent Base Project of Guizhou Province, China [FCJD2018-22], Guizhou Provincial Academician Workstation of Microbiology and Health (No. [2020]4004). Partial funding was by an international joint project from the National Natural Science Foundation of China (81720108026) and the FWF grant P 31990-B to VM which is gratefully acknowledged. V.A.V. received fellowships from CNPq (grant number 312811/2018-7), Brasilia, Brazil and from the Brazilian Federal Agency for Support and Evaluation of Graduate: Education Coordination for the Improvement of Higher Education Personnel_CAPES/PRINT project (www.capes.gov.br).

Availability of data and materials

The datasets generated for this study can be found in the GenBank Accessions: JACJVS000000000 (I. delicatus) and JACJVT000000000 (I. lentus).

\section{Declarations}

Ethics approval and consent to participate Not applicable.

Consent for publication

Not applicable.

\section{Competing interests}

The authors declare that they have no competing interests.

\section{Author details}

${ }^{1}$ Center of Expertise in Mycology of Radboud University Medical Center/Canisius Wilhelmina Hospital, Nijmegen, The Netherlands. ${ }^{2}$ Department of Dermatology and Laboratory of Medical Mycology, Jining No. 1 People's Hospital, Shandong, China. ${ }^{3}$ Key Laboratory of Environmental Pollution Monitoring and Disease Control, Ministry of Education of Guizhou and Guizhou Talent Base for Microbiology and Human Health, School of Basic Medical Sciences, Guizhou Medical University, Guiyang, China. ${ }^{4}$ Guizhou Provincial Academician Workstation of Microbiology and Health, and Guizhou Academy of Tobacco Science, Guiyang, China. ${ }^{5}$ Graduate Program in Microbiology, Parasitology 
and Pathology, Biological Sciences, Department of Basic Pathology, Federal University of Paraná, Curitiba, Brazil. ${ }^{6}$ Department of Botany and Biodiversity Research, University of Vienna, Wien, Austria. ${ }^{7}$ Graduate Program in Bioprocess Engineering and Biotechnology, Federal University of Paraná, Curitiba, Brazil.

\section{Received: 2 September 2021 Accepted: 23 February 2022} Published online: 07 March 2022

\section{References}

Attili-Angelis D, Duarte A, Pagnocca F, Nagamoto N, De Vries M, Stielow J, de Hoog G (2014) Novel Phialophora species from leaf-cutting ants (tribe Attini). Fungal Diversity 65(1):65-75

Bailey IW (1920) Some relations between ants and fungi. Ecology 1(3):174-189 Biedermann PH, Vega FE (2020) Ecology and evolution of insect-fungus mutualisms. Annu Rev Entomol 65:431-455

Blin K, Shaw S, Steinke K, Villebro R, Ziemert N, Lee SY, Medema MH, Weber T (2019) antiSMASH 5.0: updates to the secondary metabolite genome mining pipeline. Nucleic Acids Res 47(W1):W81-W87

Cantarel BL, Coutinho PM, Rancurel C, Bernard T, Lombard V, Henrissat B (2009) The Carbohydrate-Active EnZymes database (CAZy): an expert resource for glycogenomics. Nucleic Acids Res 37(suppl_1):D233-D238

Chadha S, Mehetre ST, Bansal R, Kuo A, Aerts A, Grigoriev LV, Druzhinina LS, Mukherjee PK (2018) Genome-wide analysis of cytochrome P450s of Trichoderma spp.: annotation and evolutionary relationships. Fungal Biol Biotechnol 5(1):12-28

Chomicki G, Renner SS (2015) Phylogenetics and molecular clocks reveal the repeated evolution of ant-plants after the late Miocene in Africa and the early Miocene in Australasia and the Neotropics. New Phytol 207(2):411-424

Chomnunti P, Bhat D, Jones EG, Chukeatirote E, Bahkali AH, Hyde KD (2012) Trichomeriaceae, a new sooty mould family of Chaetothyriales. Fungal Divers 56(1):63-76

Coppin E, Debuchy R, Arnaise S, Picard M (1997) Mating types and sexual development in filamentous ascomycetes. Microbiol Mol Biol Rev 61(4):411-428

David ME (2009) Trail pheromones of ants. Physiol Entomol 34(1):1-17

Defossez E, Selosse MA, Dubois MP, Mondolot L, Faccio A, Djieto-Lordon C, McKey D, Blatrix R (2009) Ant-plants and fungi: a new threeway symbiosis. New Phytol 182(4):942-949

Di Mauro G, Perez M, Lorenzi MC, Guerrieri FJ, Millar JG, d'Ettorre P (2015) Ants discriminate between different hydrocarbon concentrations. Front Ecol Evol 3:133

Diallo A, Michaud C, Tabibou S, Raz M, Fernandez C, Lepidi H, Fournier P-E, Stein A, Ranque S, Seng P (2017) Case report: Arthrocladium fulminans arthritis and osteomyelitis. Am J Trop Med Hyg 96(3):698

Döğen A, Ilkit M, De Hoog GS (2013) Black yeast habitat choices and species spectrum on high altitude creosote-treated railway ties. Fungal Biol 117(10):692-696

Egenlauf B, Schuhmann M, Giese T, Junghanss T, Stojkovic M, Tintelnot K, de Hoog S, Greil J, Richter E, Vehresschild M (2019) Disseminated mycosis by Arthrocladium fulminans jeopardizing a patient with GATA2 deficiency. Respiration 97(5):472-475

Fraser JA, Stajich JE, Tarcha EJ, Cole GT, Inglis DO, Sil A, Heitman J (2007) Evolution of the mating type locus: insights gained from the dimorphic primary fungal pathogens Histoplasma capsulatum, Coccidioides immitis, and Coccidioides posadasii. Eukaryot Cell 6(4):622-629

Gostinčar C, Muggia L, Grube M (2012) Polyextremotolerant black fungi: oligotrophism, adaptive potential, and a link to lichen symbioses. Front Microbiol 3:390

Huxley CR (1978) The ant-plants Myrmecodia and Hydnophytum (Rubiaceae), and the relationships between their morphology, ant occupants, physiology and ecology. New Phytol 80(1):231-268

Isola D, Selbmann L, de Hoog GS, Fenice M, Onofri S, Prenafeta-Boldú FX, Zucconi $L$ (2013) Isolation and screening of black fungi as degraders of volatile aromatic hydrocarbons. Mycopathologia 175(5-6):369-379

Keller NP, Turner G, Bennett JW (2005) Fungal secondary metabolism-from biochemistry to genomics. Nat Rev Microbiol 3(12):937-947

Kweon O, Kim S-J, Kim JH, Nho SW, Bae D, Chon J, Hart M, Baek D-H, Kim Y-C, Wang W (2020) CYPminer: an automated cytochrome P450 identification, classification, and data analysis tool for genome data sets across kingdoms. BMC Bioinform 21(1):1-11

Little AE, Currie CR (2007) Symbiotic complexity: discovery of a fifth symbiont in the attine ant-microbe symbiosis. Biol Lett 3(5):501-504

Mayer VE, Nepel M, Blatrix R, Oberhauser FB, Fiedler K, Schönenberger J, Voglmayr H (2018) Transmission of fungal partners to incipient Cecropia-tree ant colonies. PLoS ONE 13(2):e0192207

Miehe H (1911) Untersuchungen über die javanische Myrmecodia. Abhandlungen Der Mathematisch-Physischen Klasse Der Königlich-Sächsischen Gesellschaft Der Wissenschaften 32:312-361

Moreau CS (2020) Symbioses among ants and microbes. Curr Opin Insect Sci 39:1-5

Moreno LF, Mayer V, Voglmayr H, Blatrix R, Stielow JB, Teixeira MM, Vicente VA, de Hoog S (2019) Genomic analysis of ant domatia-associated melanized fungi (Chaetothyriales, Ascomycota). Mycol Prog 18(4):541-552

Moreno LF, Menezes da Silva N, Weiss VA, de Fátima CF, Bittencourt JV, Macedo LM, Gomes RR, Souza EM, Vicente VA, Stielow B (2020) Genome sequence of the human opportunistic fungus Arthrocladium fulminans (CBS 136243). G3 Genes Genomes Genet 10(6):1817-1821

Mueller UG, Kardish MR, Ishak HD, Wright AM, Solomon SE, Bruschi SM, Carlson AL, Bacci M Jr (2018) Phylogenetic patterns of ant-fungus associations indicate that farming strategies, not only a superior fungal cultivar, explain the ecological success of leafcutter ants. Mol Ecol 27(10):2414-2434

Nepel M, Voglmayr H, Blatrix R, Longino JT, Fiedler K, Schönenberger J, Mayer VE (2016) Ant-cultivated Chaetothyriales in hollow stems of myrmecophytic Cecropia sp. trees-diversity and patterns. Fungal Ecol 23:131-140

Paoletti M, Seymour FA, Alcocer MJ, Kaur N, Calvo AM, Archer DB, Dyer PS (2007) Mating type and the genetic basis of self-fertility in the model fungus Aspergillus nidulans. Curr Biol 17(16):1384-1389

Quan Y, Ahmed SA, da Silva NM, Al-Hatmi AM, Mayer VE, Deng S, Kang Y, de Hoog GS, Shi D (2020a) Novel black yeast-like species in chaetothyriales with ant-associated life styles. Fungal Biol 125(4):276-284

Quan Y, Muggia L, Moreno LF, Wang M, Al-Hatmi AM, da Silva MN, Shi D, Deng S, Ahmed S, Hyde KD, de Hoog S (2020b) A re-evaluation of the Chaetothyriales using criteria of comparative biology. Fungal Divers 103(1):47-85

Schlick-Steiner BC, Steiner FM, Konrad H, Seifert B, Christian E, Moder K, Crozier $\mathrm{RH}$ (2008) Specificity and transmission mosaic of ant nest-wall fungi. Proc Natl Acad Sci 105(3):940-943

Schultz TR (2000) In search of ant ancestors. Proc Natl Acad Sci 97(26):14028-14029

Stanke M, Waack S (2003) Gene prediction with a hidden Markov model and a new intron submodel. Bioinformatics 19(2):ii215-ii225

Teixeira MdM, Moreno LF, Stielow B, Muszewska A, Hainaut M, Gonzaga L, Abouelleil A, Patané J, Priest M, Souza R (2017) Exploring the genomic diversity of black yeasts and relatives (Chaetothyriales, Ascomycota). Stud Mycol 86:1-28

Vasse M, Voglmayr H, Mayer V, Gueidan C, Nepel M, Moreno L, de Hoog S, Selosse M-A, McKey D (1850) Blatrix R (2017) A phylogenetic perspective on the association between ants (Hymenoptera: Formicidae) and black yeasts (Ascomycota: Chaetothyriales). Proc R Soc B Biol Sci 284:20162519

Voglmayr H, Mayer V, Maschwitz U, Moog J, Djieto-Lordon C, Blatrix R (2011) The diversity of ant-associated black yeasts: insights into a newly discovered world of symbiotic interactions. Fungal Biol 115(10):1077-1091

Zhang H, Yohe T, Huang L, Entwistle S, Wu P, Yang Z, Busk PK, Xu Y, Yin Y (2018) dbCAN2: a meta server for automated carbohydrate-active enzyme annotation. Nucleic Acids Res 46(W1):W95-W101

\section{Publisher's Note}

Springer Nature remains neutral with regard to jurisdictional claims in published maps and institutional affiliations. 